\title{
Virtual Reality and BIM Methodology as Teaching- Learning Improvement Tools for Sanitary Engineering Courses
}

\author{
https://doi.org/10.3991/ijet.v16i06.13535 \\ Verónica Paola Rossado Espinoza ${ }^{(凶)}$, Daniel Cárdenas-Salas, \\ Angela Cabrera, Lucía Coronel \\ University of Lima, Lima, Peru \\ vrossado@ulima.edu.pe
}

\begin{abstract}
Virtual Reality (VR) is often used to describe a 3D environment wherein objects and images of the real world are simulated through technology. In architectural or civil engineering, the design process with 2D planes could lead to error owing to misinterpretation in the visualization of elements. The civil engineering program of a university in Lima, Peru, mandates the teaching of the building information modeling (BIM) methodology in all the courses, thereby allowing the students to learn about the organization and optimization of projects from the design phase to construction phase. The engineering students are required to manage many variables with the BIM methodology, especially in mechanical, electrical, and plumbing systems. Nevertheless, the teaching method of BIM could be enriched by analyzing 3D project models using VR. Whereas BIM organizes and optimizes a project through a 3D model, VR can introduce the user to a model that is very close to the reality, thereby improving the interpretation and analysis of the details. This study contributes to the implementation of a plumbing engineering course under a civil engineering program. The proposed methodology was applied in an experimental group of undergraduate students, and the test results obtained were compared with those of a control group that had used a traditional approach. The results of this study show that students, by using the VR-BIM method proposed, can successfully visualize the accessories and recognize a satisfactory design in a creative and innovative manner.
\end{abstract}

Keywords - Virtual design, BIM, plumbing systems, virtual reality, architecture, civil engineering

\section{Introduction}

The world has witnessed technological advances in many areas, affecting our lives: social, educational, and industrial. According to Stals et al. [1], in the early 21 st century, a new generation of tools (such as parametric software) began to emerge that deeply impacted the design processes for architectures and engineering applications, thereby defining a parametric design as a methodology that enables one, among other 
things, to create forms based on the exploitation and manipulation of a large amount of environmental, acoustic, structural, social, or urban data recorded as 'parameters'. These methodologies are gradually transforming the construction industry and building design processes with 3D models, such as the building information modeling (BIM). Raiola [2], while discussing architectural engineering construction (AEC), states that the advantage of BIM lies in its ability to reshape the workflow of the design and construction processes through the virtual design of a structure. Historically, workflow was linear (pass-over method); i.e., one AEC discipline finishes and passes work to another discipline (p.1).

The BIM methodology endows a project team the ability to coordinate and collaborate in real-time design. Zaker et al. [3] affirmed that collaboration is a key factor for successful project delivery and that lack of a comprehensive and efficient collaborative workflow may cause delays, attract extra costs, and deteriorate the project quality (p.2). A successful project often depends on an adequate visualization on different media: a computer screen or multimedia projector. The mechanical electrical and plumbing (MEP) components are generally located in the building space. According to Ganapathi [4], visualizing MEP components on a single screen is significantly challenging because the user has to constantly tilt the model to change the orientation for bringing the overhead components to the current focus (p.2).

Wang et al. [5] asserted that two-dimensional (2D) drawing was a common form to show the basic layout of all the areas of a proposed building design; however, the owners could only obtain simple architecture geology information and building location and layout information from a 2D drawing. Likewise, for engineering students, the interpretation and visualization of floorplans are highly complicated, especially when they have to analyze several variables on a computer screen. Badrinath et al. [6] stated that prior to the industrial revolution, the architect was the master of all the practices involved in the building process. However, with modern trends and industrialization, a paradigm shift occurred to a multiplicity of specializations in the field of architecture: this shift has altered the teaching and training processes for architecture students (p.11).

If virtual reality (VR) tools were used to simulate projects and analyze alternative solutions, architects, engineers, or owners would be able to improve the design process. Richert et al. [7] studied the challenges that the future engineers will face and their need to acquire new qualifications and specialized skills; their findings showed that virtual learning environments "bear a promising potential for the successful implementation of virtual worlds within higher education." In [8], the authors verified that upon using virtual laboratories in the fields of chemistry and molecular biology, the link between the theory and practice was reinforced. According to Wang et al [9], VR technologies have been rapidly recognized in construction engineering education and training programs because of its effectiveness in enhancing the quality of such programs (p.1). VR enables students to discover and explore their knowledge. It also makes the learning process more interesting, as it motivates students and improves their attention. The findings of Alfalah [10] revealed that technology training may be optimized for the integration of the VR technology (p.1). 
This study proposes a teaching methodology with BIM using VR to develop a satisfactory plumbing engineering system design. It further presents the manner in which BIM-VR can promote collaborative working and facilitate the learning of a plumbing engineering course. The new method was tested on an experimental group of architecture students.

\section{Literature Review}

\subsection{Virtual reality and BIM}

Within computer science, the field of VR dates back to the early 1960s when the first applications were created allowing combat pilots to be trained under simulated flying conditions. The goal of VR is to entirely replace the real world with a virtually generated reality that provides the subject with an immersive experience. Broadly, VR can be used in different types of experiences, including architecture and civil engineering. According to Whyte [11], VR has the potential to improve the visualization of building design and construction, although its implementation in the industry is yet to reach maturity (p.1).

In the field of education, students traditionally need to possess advanced visual thinking skills to create 3D models, although this is not always the case for all students. The application of the BIM methodology makes a civil engineering curriculum comprehendible to students that lack this skill, that too without avoiding the traditional learning methods [12]. At the university level, future engineers experience several difficulties while learning plumbing designs. One of these difficulties is to identify the correct usages of accessories and connectors in a plumbing project.

However, the BIM methodology involves different technologies for project management through a 3D model. The collaborative workflow with BIM allows for the coordination and development of the design at all the stages of construction, improving the overall construction process. This methodology can become a powerful and attractive approach for designers and engineering students. If BIM is used with the VR technology, buildings and high-quality scenarios can be recreated, as demonstrated by Zaker et al. [3], introducing people to an almost real world. Greenwood et al. [13] demonstrated that it was advantageous to use BIM-VR to examine a building from different perspectives, as the approach improved the traditional visualization methods.

Hempe [14] highlighted that the concepts and prototypical implementations realized thus far already had demonstrated that a modern multi-domain VR simulation system could provide not only accurate simulations at the scientific level but also attractive, high-quality visualizations for the comprehensive understanding of the results (p.225). Indeed, people can be isolated from any external stimulus by using certain specialized devices that create a credible and natural reality that the subject can interact with.

Furthermore, Asgari et al. [14] stated that the integration of sensor technologies into BIM would shift the focus to the construction field. Investment in the IT sensing 
technologies would result in major cost and time savings and provide higher control and safety than before (p.1132).

Technological advances applied to the architecture design and construction processes ensure the quality and optimal operation of a building. Using new tools enhances the professional work quality of all the project members. According to Wang et al [16], visualization can improve a user's cognition and facilitate communication while discussing an abstract concept or physical object from the viewpoint of realworld situations. VR, which is an immersive multimedia technology, uses VR headsets to create realistic images, sounds, and other sensations to simulate a user's physical presence in a virtual environment such that the user can interact with digital objects in real time (p.3). The system proposed by Wang was applied to a case project located in Northern Taiwan by using a VR model with 3D information to perform field quality inspections. In their application, the VR model could be freely toured with the construction project team to learn in advance what needed to be checked. Sampaio [17] stated that introducing VR interactive capabilities into 3D/BIM models in the construction process was the main way to virtually test and correct a construction project before the realization thereof, as the walkthrough and the visualization of data linked to each parametric object were available, thereby improving the necessity collaboration within the design team (p.77).

\subsection{Virtual reality and education}

According to Nersesian et al. [18], educational technologies have the potential to improve learning, not only as a collaborative tool but also as a simulation application. As a means to complement the traditional teaching methodologies, they performed comparison between monitor-based (MB) technologies, like animations and video games, and VR educational technologies. Accordingly, they compared three teaching technologies, namely, MB, VR, and traditional, among one another, and evaluated the comprehension of chemistry topics among 300 third-year K12 students in NJ, USA, for 18 weeks. Their results showed that the students that used the VR technology obtained better final exam grades, and these students could also understand the chemistry concepts better by visualizing microscopic chemical interactions (p.89).

In other STEM related study [19], a cell biology class of 65 students participated in a 12-min VR experience workshop called "Journey Inside a Cell" created by The Body VR (http://thebodyvr.com/products/), which allowed the students to "manipulate" cells, navigate through the virtual environment, and even "shoot" antibodies into virus cells. The researchers emphasized that "cell biology is a challenging course, significantly exacerbated by the fact that a cell is so tiny that its parts cannot be viewed under a typical light microscope" (p.1). While this study did not measure the students' academic outcomes, it did conduct a voluntary survey to measure their perceived VR experiences and to find whether the VR experience had affected their learning process. The results indicated that $90 \%$ of the students considered that VR enhanced their learning experience in the cell biology course, and that $95 \%$ of them would recommend using VR technologies in other courses as well. 
Huang et al. [20] aimed to assess which technology, augmented reality (AR) or $\mathrm{VR}$, had a more profound effect on the retention of science information. To that end, they tested the science-knowledge retention of 109 college students upon exposing them to auditory and visual information. The students, from a large university in the United States, were divided in two groups (57 in the AR group and 52 in the VR group) and used a model of the solar system. The study results showed that, although $\mathrm{AR}$ seemed to be a more effective mechanism for communicating auditory information, VR was more immersive and engaging owing to its mechanism of spatial presence.

Finally, Tsichouridis et al. [21] performed an extensive literature review to gather the state of the art regarding the use of VR and AR laboratories in the field of science teaching and learning. They aimed to investigate the extent to which VR and AR environments had been investigated in that field, and they also intended to explore the relative effectiveness of both techniques (p.195) during the actual educational practice. While they identified and reviewed 19 papers dating from the year 2008 to 2017 , there were 7 papers (specifically related to tertiary education) whose findings were as diverse as showing an increased spatial competence, better conceptual perceptions, improved practical and cognitive skills, and an excellent interactive and practical experience with positive learning outcomes. The researchers concluded that educational VR and AR contents simulate the reality so closely that it is becoming increasingly difficult to differentiate between VR/AR and the reality, although there is still a room to investigate the optimum use of VR and AR.

\section{$3 \quad$ Methodology and Procedure}

This study presents the findings from an experimental study for the application of BIM to solve plumbing engineering systems using VR. The hypothesis: teaching the BIM methodology using VR can improve the design skills of architecture students in solving plumbing engineering systems. We have applied an experimental method, with qualitative and quantitative approaches. For this method, two groups of 22 and 21 architecture students enrolled in a plumbing engineering course were selected. This research complied with the local laws and has received approval from the institutional review board.

The experimental project was applied to two groups of third-year architecture students during one semester. Initially, a quantitative method was employed as a pre-test in the classroom among students. The results were compared with those of a post-test after the application of the BIM-VR method. The control group maintained its traditional teaching form. The experimental group used 21 students, while the control group had 22 students (see Figure 1). 


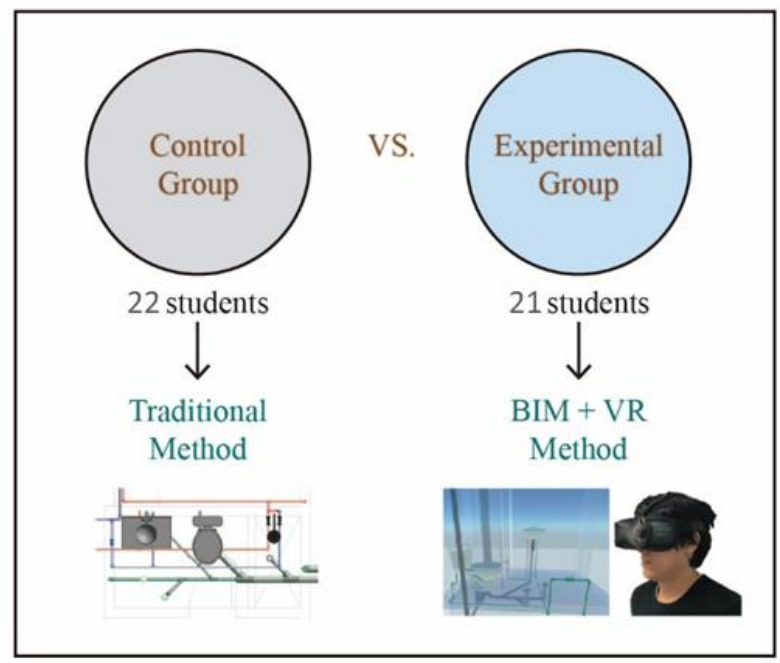

Fig. 1. Methods applied during the experimental phase

The quantitative test results were statistically analyzed. They revealed the impact of the method in the classroom and verify the research hypothesis.

The study used Unity 3D editor (version 2018.3.9); the scripts were written in C\# (version 7.3), and the BIM models were designed in Revit Architecture (version 2018). The students used VR devices to view different models and plumbing system solutions for typical private and public toilets. The VR device used for the experiment was a Samsung Gear VR, selected because of its relatively low price and a better immersive experience (compared with the extremely low-cost devices like Google Cardboard) owing to the strap that kept the Gear VR securely on the wearer's face and the foam cushioning that helped prevent too much light from seeping in. This device also uses a single small hand-held controller that was configured to command the point-of-view movements of the student inside the virtual model (see Figure 2). Noteworthily, this VR device relies on a cellular phone to work, and thus we employed a Samsung Galaxy S8 smartphone, which was considered a high-end device at the time of the experiment.
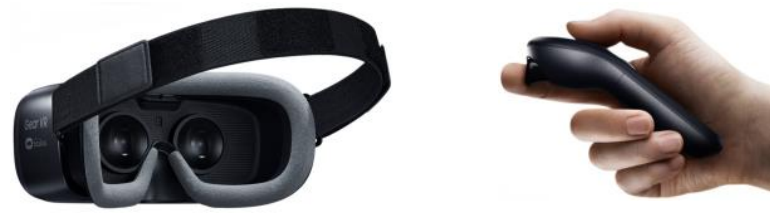

Fig. 2. Virtual Reality device used (left) and the accompanying controller (right, not to scale)

In the house model, students were asked to visualize the best plumbing solutions in different sectors: kitchens, bathrooms, swimming pool systems, and laundry. This 
environment emphasized water connections and drainage systems. The systems for hot water, cold water, and drainage, respectively, used different highlighted colors and tags with connectors and accessory names (see Figure 3).

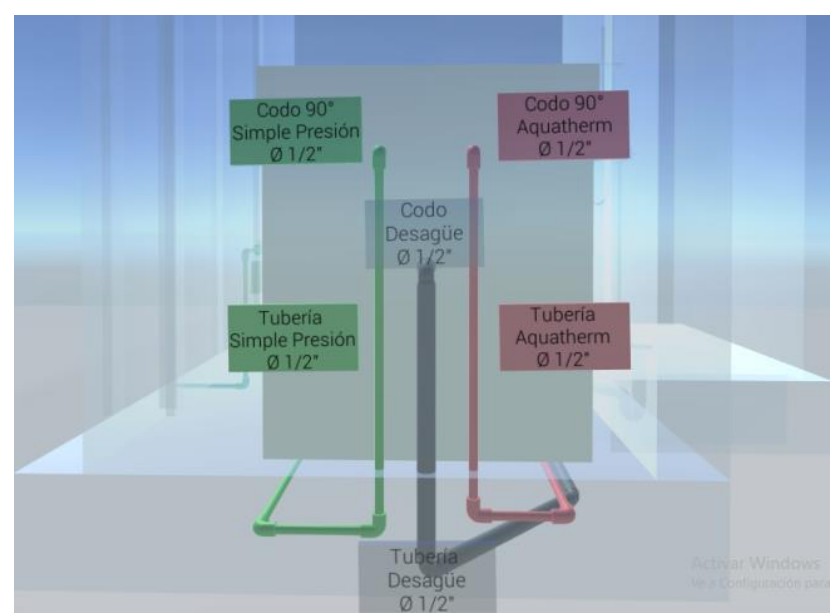

Fig. 3. Bathroom model with plumbing networks

\subsection{Research activities}

The research process was divided into the following activities:

1. Survey the teachers to recognize the importance of the research topic

2. Identify the problems experienced by student in solving plumbing engineering systems

3. Design a teaching method to solve the problems experienced

4. Prepare BIM models with several plumbing solutions

5. Generate a VR environment with BIM plumbing systems using Unity 3D

6. Divide the students into two study groups

7. Apply the pre-test in the control and experimental student groups

8. Perform network simulation using VR

9. Apply the post-test to the control and experimental student groups after applying the teaching method in the experimental group

10. Process and analyze the results of the experimental project

11. Reformulate and readjust the method on the basis of the results obtained

A descriptive method was used to study the data of the questionnaire in both the groups. The qualitative and quantitative results obtained confirmed that VR systems could be included as a teaching-learning aid in plumbing engineering courses, with a positive effect on student learning. However, a small group of students in the experimental test preferred the traditional method, stating that the use of VR was not necessary to understand the development of water networks but only more useful in solving drainage system problems. 


\subsection{Data collection and analysis}

Chalhoub [22] stated that it was not clear how this mode of visualization would impact the performance of the practitioner (p.1-2). This research attempts to address the following: How can BIM-VR influence the quality of the teaching-learning process in plumbing engineering courses? An experimental procedure was designed. The target audience were third-year architecture students enrolled in a plumbing engineering course. As a pre-requisite for participation in the study, the students had basic skills in reading architectural plans. Two groups were formed: group A with 22 students and group B with 21 students. The participants performed similar tasks by using BIM-VR and the traditional method, respectively. All the activities were scheduled in two phases: the first one evaluated the topic of cold and hot water networks, while the second one evaluated the topic of sanitary networks. The backgrounds and perceptions of the students were identified and analyzed by tests and surveys (see Figure 4).

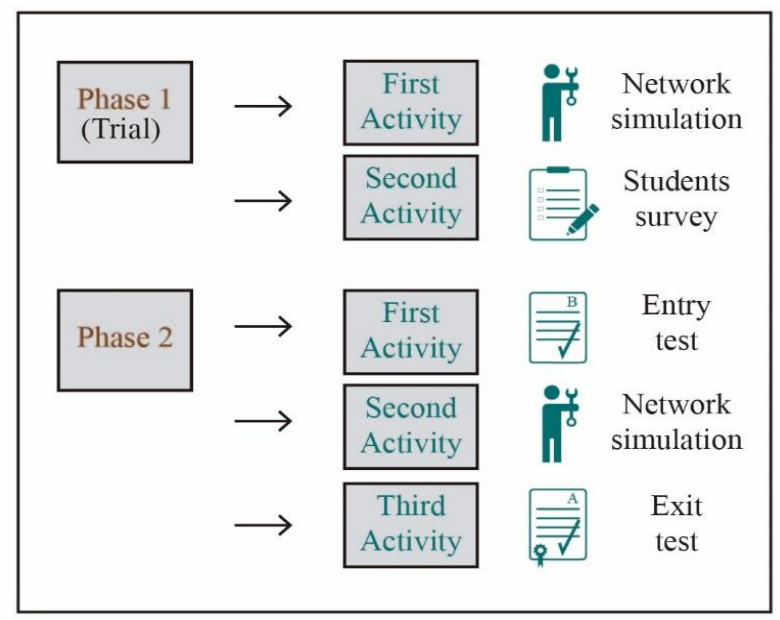

Fig. 4. Experimental procedure for data collection

\subsection{Phase 1: Fist activity}

The first activity was executed during the fifth academic week when the students had visited the construction laboratory to participate in a network simulation. The goal of this activity was to build cold and hot water networks. During this phase, the behaviors of the students were observed and documented, including the task performed by each member, the time spent during the activity, and their spontaneous reaction to the use of VR. Images and handwritten notes by the teacher were also taken as a part of the documentation.

The students from group A were distributed into five sub-groups according to their personal preferences. Each group received a paper plan with information of a bathroom and its cold and hot network design. All the five sub-groups received a VR device to view the same bathroom with the sanitary network model. 
The tasks performed by each participant were identified. In case 1, the main task of the subject was to collect items needed for the network simulation and to assemble them. In case 2, the students visualized the model for approximately $30 \mathrm{~s}$ and then switched to another task. In case 3, the students had the task of using the VR device to verify whether the network being built was correct; if not, the participant showed where the mistakes were located. This type of behavior denoted some leadership skills. Case 4 was more participatory in nature, as the students temporarily had initially the same task and then changed to another task.

An unexpected behavior was detected: one sub-group preferred to use paper plans instead of working with the VR device. This behavior could be attributed to the topranking students of the class, as they might have considered themselves selfsufficient, hence regarding the technology as unnecessary to achieve the goal. This situation was similar to the one that occurred in Chalhoub's [22] research about mixed reality (MR) in which he quotes, "nearly all the participants agreed that MR was easy to use, although most still felt that they would prefer to use paper plans" (p.1).

Although all the sub-groups could correctly build water networks within the class duration (i.e., $100 \mathrm{~min}$ ), the sub-groups that used the VR devices achieved the most detailed assembled models.

\subsection{Phase 1: Second activity}

During the ninth academic week, a survey about visualization was conducted among 21 students of the experimental group, revealing that $42 \%$ agreed that the use of paper plans was sufficient to obtain the knowledge of the design required for the plumbing engineering course. However, $79 \%$ deemed 3D visualization as necessary in better understanding the course, and $60 \%$ opined that 3D designs help visualize errors in models. Additionally, $84 \%$ asserted that materials and accessories could be the estimated better using a 3D model. When the participants were asked about the skills required to visualize or imagine a plumbing network by using paper plans, $48 \%$ were hesitant about it, while $42 \%$ believed that they could do it. Finally, $90 \%$ agreed that a $3 \mathrm{D}$ design was necessary to be taught during the plumbing engineering course (see Figure 5).

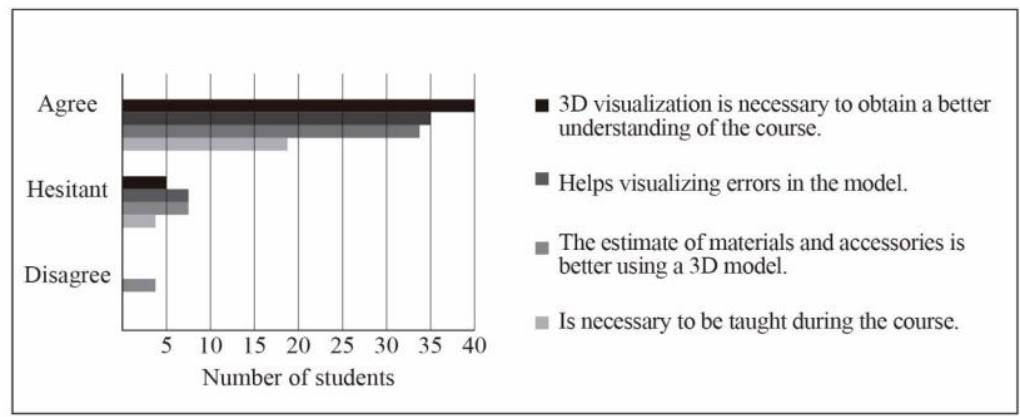

Fig. 5. Survey answers about incorporating a 3D technology in the plumbing engineering courses 
Additionally, 64\% had previously heard about the BIM methodology; 96\% considered it as a resource that reduces the number of mistakes in a project; $89 \%$ considered that this tool contributes to the learning process of a plumbing engineering course. Finally, $85 \%$ agreed with the use of tools, such as VR, allowing students to visualize plumbing networks in real scale (see Figure 6).

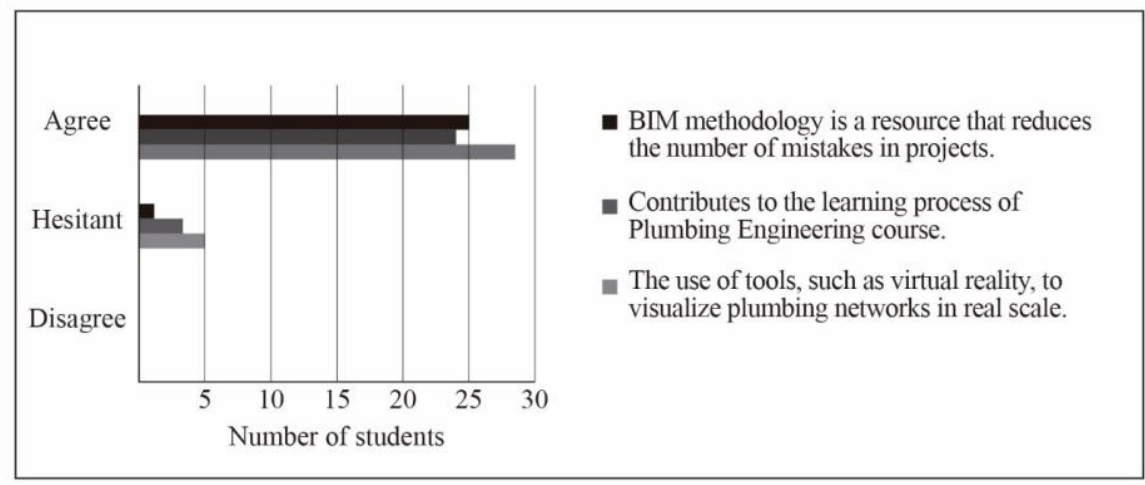

Fig. 6. Survey on the use of the BIM methodology in plumbing engineering courses

With all the previously gained experience and knowledge, phase 2 was modified with a view to obtaining reliable results. For this phase, group A was selected as the control group and group B as the experimental group. The control group used the traditional method, and the experimental group combined the same traditional method with VR. In this phase, we collected and evaluated information about three activities: network simulation, entry test, and exit test.

\subsection{Phase 2: First activity}

The entry test was performed during the ninth academic week when the students participated in an evaluation test to assess their knowledge about the subject. Data were collected from the 22 students of the control group and 21 students of the experimental group. The students were graded in a scale of 0 to 20 , where the grade of 10.50 or higher was considered a passing grade. In the entry test, the control group passed by obtaining an average grade of 10.61, and the experimental group failed by obtaining an average grade of only 9.455 . To validate the statistical significance of the results, Bonett's method and Levene's method were applied with a significance level of 0.05 (see Table 1). These methods were valid for any continuous distribution of the entry test. The results are shown in Figure 7. 
Table 1. Statistical significance analysis of the entry test for the control and experimental groups

\begin{tabular}{|c|c|c|c|c|c|}
\hline \multicolumn{6}{|c|}{ Descriptive statistics } \\
\hline \multicolumn{6}{|c|}{$\sigma_{1}:$ standard deviation of the control group } \\
\hline \multicolumn{6}{|c|}{$\sigma_{2}:$ standard deviation of the experimental group } \\
\hline \multicolumn{6}{|c|}{ Ratio: $\sigma_{1} / \sigma_{2}$} \\
\hline Variable & $\mathbf{N}$ & St. Dev. & Variance & \multicolumn{2}{|c|}{$95 \%$ CI for $\sigma$} \\
\hline Control & 22 & 5.272 & 27.794 & \multicolumn{2}{|c|}{$(4.224 ; 7.194)$} \\
\hline Experimental & 21 & 3.764 & 14.165 & \multicolumn{2}{|c|}{$(2.881 ; 5.398)$} \\
\hline \multicolumn{6}{|c|}{ Ratio of Standard Deviations } \\
\hline \multicolumn{2}{|l|}{ Estimated Ratio } & \multicolumn{2}{|c|}{$\begin{array}{c}95 \% \text { CI for ratio } \\
\text { using Bonett's method }\end{array}$} & \multicolumn{2}{|c|}{$\begin{array}{c}\text { 95\% CI for ratio } \\
\text { using Levene's method }\end{array}$} \\
\hline 1.40081 & & & 170) & & $.259)$ \\
\hline \multicolumn{6}{|c|}{ Test } \\
\hline \multicolumn{2}{|l|}{ Null hypothesis } & \multicolumn{4}{|c|}{$\mathrm{H}_{0}: \sigma_{1} / \sigma_{2}=1$} \\
\hline \multicolumn{2}{|l|}{ Alternative hypothesis } & \multicolumn{4}{|c|}{$H_{1}: \sigma_{1} / \sigma_{2} \neq 1$} \\
\hline \multicolumn{2}{|l|}{ Significance level } & \multicolumn{4}{|l|}{$x=0.05$} \\
\hline Method & & Statistics & DF1 & $D F 2$ & $p$-value \\
\hline Bonett's & & $*$ & & & 0.091 \\
\hline Levene's & & 1.46 & 1 & 43 & 0.234 \\
\hline
\end{tabular}

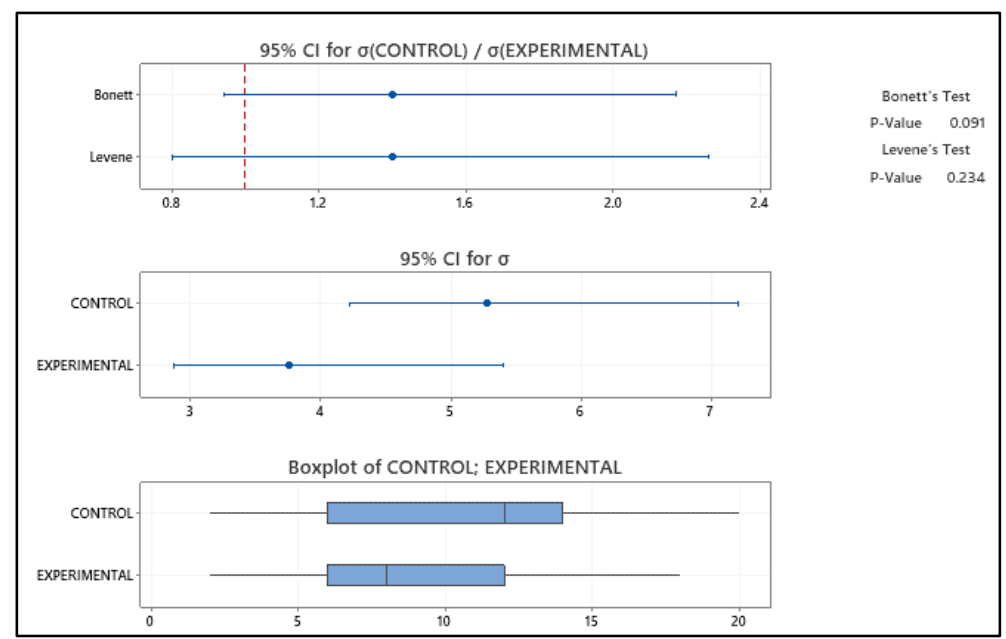

Fig. 7. Entry test and CI for two variances: control and experimental $($ ratio $=1$ vs ratio $\neq 1)$

\subsection{Phase 2: Second activity}

The 2 nd activity was performed on the 11th academic week when the students visited the construction laboratory to participate in a network simulation, similar to the visit during the previous phase. This activity aimed to build sanitary networks. The students from the control group were organized into five sub-groups according to their personal preferences; each group received a paper plan, which contained information 
about a bathroom and its sanitary network design. The students built the network without using any VR device, based on the proposed methodology. The students from the experimental group were also organized into five sub-groups according to their personal preferences, and all of them also received a paper plan with the same information as that received by the control group students. In this case, each of the four sub-groups received a VR device, on which they saw the bathroom with the sanitary networks, while another group could not use the device owing to limited supply. During the activity, the behaviors of the students were observed and documented like in the previous phase.

\subsection{Phase 2: Third activity}

The last activity was performed during the 30th academic week when the students participated in an evaluation test to determine their obtained knowledge. Data from the 22 control group students and 21 experimental group students were collected, considering the same qualification criteria as those for the entry test. For this test, the control group obtained an average grade of 12.91 and the experimental group an average grade of 16.10 .

The population size was 67 students who were enrolled in the plumbing engineering course in the second semester of 2018. The sample size was 35 students considering a confidence level of $95 \%$ and an error margin of $12 \%$. Noteworthily, some other variables, including but not limited to, that could affect the experimental results are as follows: disinterest among the students to participate in the tests (resulting in them not obtaining a satisfactory score in the course), or the fatigue that decreases the performance of the students during the tests.

Table 2. Statistical significance analysis of the exit test for the control and experimental groups

\begin{tabular}{|c|c|c|c|c|c|}
\hline \multicolumn{6}{|c|}{ Descriptive statistics } \\
\hline \multicolumn{6}{|c|}{$\sigma_{1}:$ standard deviation of the control group } \\
\hline \multicolumn{6}{|c|}{$\sigma_{2}:$ standard deviation of the experimental group } \\
\hline \multicolumn{6}{|c|}{ Ratio: $\sigma_{1} / \sigma_{2}$} \\
\hline Variable & $\mathbf{N}$ & St. Dev. & Variance & \multicolumn{2}{|c|}{$95 \%$ CI for $\sigma$} \\
\hline Control & 22 & 5.546 & 30.753 & \multicolumn{2}{|c|}{$(4.830 ; 6.990)$} \\
\hline Experimental & 21 & 3.192 & 10.190 & \multicolumn{2}{|c|}{$(2.829 ; 3.973)$} \\
\hline \multicolumn{6}{|c|}{ Ratio of Standard Deviations } \\
\hline Estimated Ratio & & \multicolumn{2}{|c|}{$\begin{array}{c}\text { 95\% CI for ratio } \\
\text { using Bonett's method }\end{array}$} & \multicolumn{2}{|c|}{$\begin{array}{c}\text { 95\% CI for ratio } \\
\text { using Levene's method }\end{array}$} \\
\hline 1.73719 & & \multicolumn{2}{|c|}{$(1.347 ; 2.199)$} & \multicolumn{2}{|c|}{$(1.141 ; 3.967)$} \\
\hline \multicolumn{6}{|c|}{ Test } \\
\hline Null hypothesis & & \multicolumn{4}{|c|}{$\mathrm{H}_{0}: \sigma_{1} / \sigma_{2}=1$} \\
\hline Alternative hypothesi & & \multicolumn{4}{|c|}{$H_{1}: \sigma_{1} / \sigma_{2} \neq 1$} \\
\hline Significance level & & \multicolumn{4}{|l|}{$\imath=0.05$} \\
\hline Method & & Statistic & DF1 & DF2 & p-value \\
\hline Bonett's & \multicolumn{2}{|c|}{$*$} & & & 0.000 \\
\hline Levene's & \multicolumn{2}{|c|}{6.57} & 1 & 41 & 0.014 \\
\hline
\end{tabular}




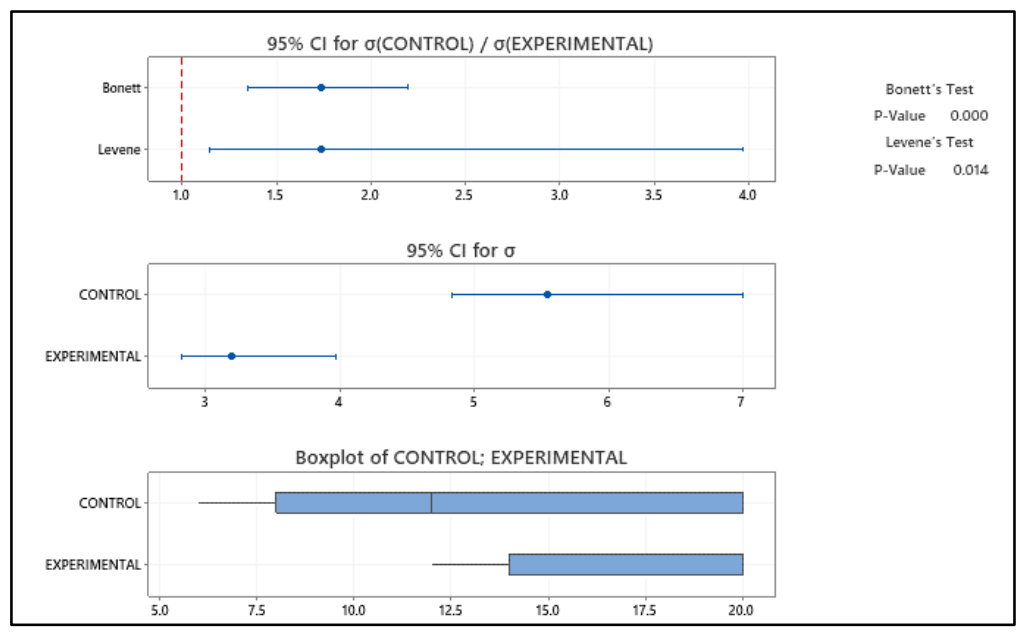

Fig. 8. Exit test and CI for two variances: control and experimental $($ ratio $=1$ vs ratio $\neq 1)$

The statistical analysis proves that the results of the exit test of the experimental group are better than those of the control group (see Tables 1 and 2). All the students considered BIM-VR as a highly useful tool, which allowed them to overcome many barriers during the design and execution processes and also provided them with an instrument to improve the quality of their work as future engineers, thereby making them stand out.

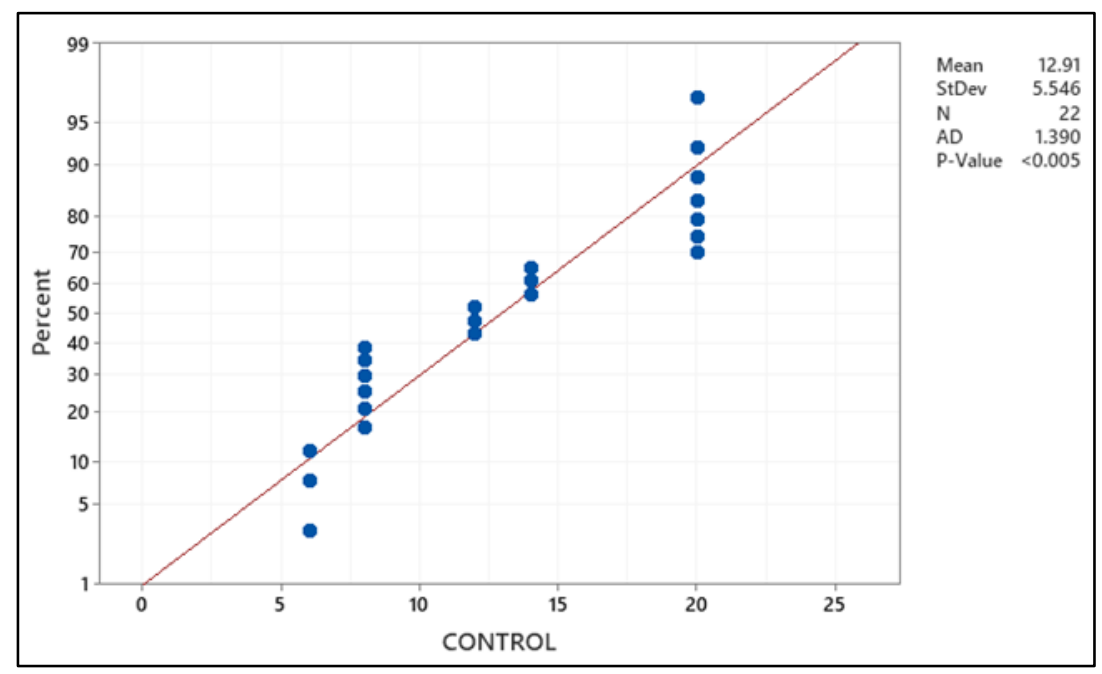

Fig. 9. Probability plot for the exit test of the control group 


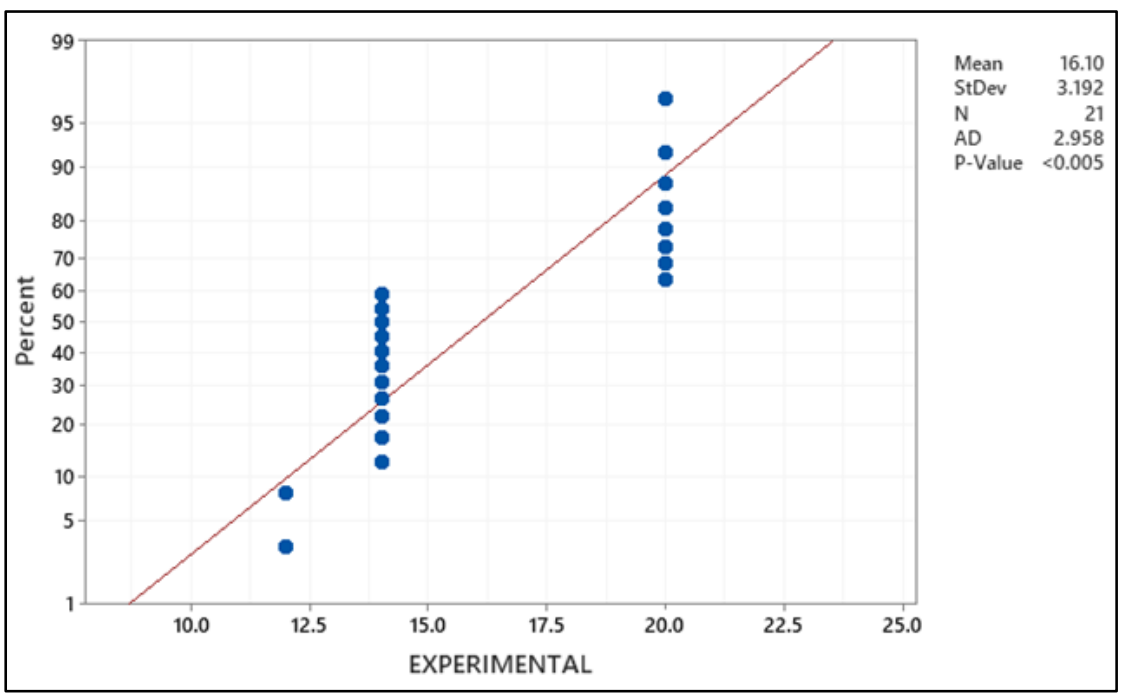

Fig. 10.Probability plot for the exit test of the experimental group

\section{$4 \quad$ Results}

The experimental analysis proved the hypothesis that the BIM teaching methodology using VR can improve the design skills of architecture students and help solve plumbing engineering systems. According to Nandavar [23], the combination of BIM and VR enables "a range of interactions with the BIM model in the VR environment, making it potentially useful as a layout planning tool" (p.9). This research attempted to demonstrate the usefulness in the academic area of the BIM methodology combined with VR by applying it into a plumbing engineering course.

Remarkably, during the first test application, a small group of four students decided to solve the test without using VR devices and still achieved satisfactory results. It can be interpreted that some students do not need additional technological support; they are generally outstanding students who reject change and believe they already know the subject. However, these students can be viewed as exceptional cases because the qualitative surveys revealed that most students $(90 \%)$ considered the BIMVR method important to be taught in plumbing engineering courses.

The following activities were executed when the students used VR devices:

- Observe the behaviors of the students toward the devices

- Take images of the process

- Record the time of the experiment

- Collect test and survey data

- Analyze the data and generate statistical graphics

- Interpret the results 
After the initial experience using VR to visualize and analyze a plumbing system structure, the teams built a water system using pipes, connectors, and accessories in a real scale. The general satisfaction level reported by the students was high when completing the tests using the BIM-VR method, demonstrating an improvement in the academic performance and positive effect in the development of the skills required by the course.

Sampaio et al. [24] proved that the VR construction model allowed the presentation of each step by comparing what was planned against the real situation observed through images taken in situ. The model, therefore, helps designers and owners redefine the early plan by introducing changes to the work in progress. Thus, economic benefits of updating the planning schedule, along with the advantages associated with a better, error-free construction with no unnecessary delays, are achieved (p. 149).

Furthermore, through the experimental project, it was proved that students can develop other competences from the attitudinal, procedural, and conceptual viewpoints.

The attitudinal-competence aspects that developed in the experimental group were as follows: communication among the students, teacher-student empathy, interest for the course, low distraction, responsibility, more effort, work and homework completion, feeling of contribution when searching for solutions, classroom teamwork organization, and better behavior.

The procedural-competence aspects that improved were as follows: working in group, learning by collaboration, visualization of plumbing systems, organization and distribution of accessories, and detailed analysis of water and drainage systems.

The conceptual-competence aspects that improved in the teaching-learning process were as follows: interest in the utilization of innovative methods, high level of research, exploration of new topics, and self-learning.

Interestingly, when interacting with the imaginary environment, the VR project participants thought they were somewhere else and lost the notion of their real physical location. Some stated that they thought of falling down the stairs or hitting a wall while using the VR device. Students recognized virtual models as the representative of what they would see in a real construction.

On the basis of the observations made during the experimentation phase of this research, it can be said that BIM-VR methods can improve the 3D visualization capabilities of students and can also reduce the gap between 2D paper plans and final implementation in a real construction process, thereby contributing to the formation of highly learned future engineers and architects.

\section{Conclusion}

According to the experimental research presented in this study, many advantages are offered upon combining VR with BIM in a plumbing engineering course. On the basis of the findings of this study, it can be said that students can successfully use the BIM-VR method to visualize plumbing accessories and recognize a satisfactory design in a creative and innovative manner. Onime, Uhomoibhi, and Pietrosemoli [25] demonstrated that this type of virtual tools enhanced "several learning outcomes in a 
practical and hands-on manner, ensuring that learners (engineers and professionals) are better equipped with the relevant skills for meeting the challenges and demands of the professional practice."

The overwhelming extent of the existing technological advances in the field of construction precludes an adequate selection of tools and a proper work methodology and skills that are included in the professional career profile, which should be acquired by students. In an industry that requires the integration of engineers, architects, builders, and clients, analytical skill development and collaborative working environment must be guaranteed during the training of the students.

The traditional methods applied to the process of teaching a construction project and its subdomains do not allow the students to quickly understand all the factors that influence the construction, as in the case of plumbing systems. Because of the significant amount of data and technical specifications that must be considered to perform the design and calculation of an efficient system consisting of hot water, cold water, and drainage, the student must clearly handle the technical information and be able to accurately present the network system in $2 \mathrm{D}$ planes. This work requires time for calculation, analysis, revision, and correction to avoid errors, where the $3 \mathrm{D}$ visualization and introduction of data with a computer support are of substantial help.

The VR experience provided the students an approach that is both dynamic and very close to the reality, thereby motivating classroom activities and creating a positive environment in which the groups worked collaboratively and showed great interest in the subject. The difficulties generally observed among students when trying to visualize a complex plumbing network can be, at least, mitigated and, at best, resolved by utilizing VR devices that translate and convert those $2 \mathrm{D}$ models to a $3 \mathrm{D}$ environments in which the user can navigate and view along different directions. Using virtual labels with technical information, along with the pipes, also helped with the educational aspect of the experience. Additionally, the ability to switch between "a transparent view" and "a more realistic view with solid walls" contributed to the understanding of how the plumbing system is implemented in relationship with the environment.

\section{Recommendations}

Technological developments applied to the design and construction processes can increase the building quality and the optimal operation thereof. Additionally, the work of the professionals involved is strengthened by using new technologies, and the necessary skills to use these technologies can be acquired early during their university training. Teachers and students have at their current disposal a myriad of tools and applications that build up their abilities at various stages of their academic lives and push them toward professional success. Because this research focused on the use of VR devices in combination with BIM, some of the recommendations for the development of a BIM-VR teaching product for a plumbing engineering course are listed as follows: 
For the BIM 3D model:

- Design a 3D project on Revit

- Design plumbing systems on Revit MEP

- Model plumbing accessories according to the national standards

- Organize and encode new pipes and families of accessories

- Develop plumbing systems for a house

- Develop plumbing systems for a typical bathroom in a house (private) and a mall (public)

- Organize the information according to the level of complexity

- Model environments that are of common use for students

For the unity system:

- Set the position of the virtual camera based on the height of an average person

- Maintain the time it takes to navigate in each simulation within reasonable limits, usually less than five minutes, so the user does not suffer from motion sickness

- Use the head tracking technology and allow the person to move along the direction he or she is looking at

- Place text labels that indicate the characteristics of the accessories

- Highlight the types of pipes by colors (for example, red for hot water pipes and blue for cold water pipes)

- Do not saturate the virtual environment with large areas or too many objects because it can affect the system performance, giving a bad experience for the user

- Use a transparent material for walls and floors to be able to see the pipes inside them

- Provide the freedom to go around anywhere they want

For the teaching materials:

- Print floorplans with system schemes

- Make a list of accessories according to their brands, models, and utilities

- Prepare several tests for each level of complexity

- Print a building model highlighting the plumbing systems

Tools used to support the plumbing design using BIM-VR:

- PC compatible with Windows or Mac for development

- Oculus VR devices

- A projector or television connected with the VR system provided a real-time experience to other students who were not using the VR devices at the moment

Photorealistic visualizations are being increasingly used in industries so that building environments can be analyzed without having to physically move. Light effects, space proportions, colors, and the details of and conflicts between plumbing or electrical systems can be analyzed by VR. Notably, VR is a new technology widely used 
in computer games, and it can also prove to be very attractive for engineering students who can learn via dynamic interactions.

\section{$7 \quad$ Acknowledgement}

This research work was financed by the Scientific Research Institute of the University of Lima. We also want to thank Marcelo Coronel Castromonte and Luis Alonso Avalo Guarderas, who were both students of the Systems Engineering Program at University of Lima during this project, for their substantial contribution to the research.

\section{References}

[1] Stals A, Jancart S, Elsen C. (2018). Influence of parametric tools on the complexity of architectural design in everyday work of SME'S. ArchNet-IJAR: International Journal of Architectural Research, 12: 206. https://doi.org/10.26687/archnet-ijar.v12i3.1665

[2] Raiola III JA. Assessment of future employment and competency skills in building information modeling: A Delphi study (Doctoral dissertation, Indiana State University).

[3] Zaker R, Coloma E. (2018). Virtual reality-integrated workflow in BIM-enabled projects collaboration and design review: a case study. Visualization in Engineering, 6: 4. https://doi.org/10.1186/s40327-018-0065-6

[4] Ganapathi, SA. (2016). Immersive virtual reality system using BIM application with extended vertical field of view (Doctoral dissertation). Badrinath AC, Chang YT, Hsieh SH. A review of tertiary BIM education for advanced engineering communication with visualization. Visualization in Engineering, 4: 1-7. https://doi.org/10.1186/s40327-016-0038-6

[5] Wang J, Wang X, Shou W, Xu B. (2014). Integrating BIM and augmented reality for interactive architectural visualisation. Construction Innovation, 14: 453-476. https://doi.org/10. $\underline{1108 / \text { ci-03-2014-0019 }}$

[6] Badrinath A, Chang Y, Hsieh S. (2016). A review of tertiary BIM education for advanced engineering communication with visualization. Visualization in Engineering, 4: 1-17. https://doi.org/10.1186/s40327-016-0038-6

[7] Richert A, Shehadeh M, Willicks F, Jeschke S. (2016). Digital transformation of engineering education-empirical insights from virtual worlds and human-robot-collaboration. International Journal of Engineering Pedagogy, 6: 23-29. https://doi.org/10.3991/ijep.v6i4.6023

[8] Qvist P, Kangasniemi T, Palomäki S, Seppänen J, Joensuu P, Natri O, Närhi M, Palomäki E, Tiitu H, Nordström K. (2015). Design of virtual learning environments: Learning analytics and identification of affordances and barriers. International Journal of Engineering Pedagogy, 5: 64-75. https://doi.org/10.3991/ijep.v5i4.4962

[9] Wang P, Wu P, Wang J, Chi HL, Wang X. (2018). A critical review of the use of virtual reality in construction engineering education and training. International Journal of Environmental Research and Public Health, 15: 1204. https://doi.org/10.3390/ijerph15061204

[10] Alfalah SF. (2018). Perceptions toward adopting virtual reality as a teaching aid in information technology. Education and Information Technologies, 23: 2633-2653. https://doi. org/10.1007/s10639-018-9734-2 
[11] Whyte J, Bouchlaghem N, Thorpe A, McCaffer R. (2000). From CAD to virtual reality: modelling approaches, data exchange and interactive 3D building design tools. Automation in construction, 10: 43-55. https://doi.org/10.1016/s0926-5805(99)00012-6

[12] Raiola III JA. Assessment of future employment and competency skills in building information modeling: A Delphi study (Doctoral dissertation, Indiana State University).

[13] Greenwood D, Horne M, Thompson EM, Allwood CM, Wernemyr C, Westerdahl B. (2008). Strategic perspectives on the use of virtual reality within the building industries of four countries. Architectural engineering and design management, 4: 85-98. https://doi.org/10.3763/aedm.2008.0076

[14] Hempe N. (2016). Bridging the gap between rendering and simulation frameworks: concepts, approaches and applications for modern multi-domain VR simulation systems. Springer. https://doi.org/10.1007/978-3-658-14401-2_3

[15] Asgari Z, Rahimian FP. (2017). Advanced virtual reality applications and intelligent agents for construction process optimisation and defect prevention. Procedia engineering, 196: 1130-1137. https://doi.org/10.1016/j.proeng.2017.08.070

[16] Wang KC, Wang SH, Kung CJ, Weng SW, Wang WC. Applying BIM and visualization techniques to support construction quality management for soil and water conservation construction projects. InISARC. Proceedings of the International Symposium on Automation and Robotics in Construction 2018 (Vol. 35, pp. 1-8). IAARC Publications. https://doi.org/10.22260/isarc2018/0099

[17] Sampaio AZ. Enhancing BIM methodology with VR technology. InState of the Art Virtual Reality and Augmented Reality Knowhow 2018 Apr 12 (pp. 59-79). London: IntechOpen. https://doi.org/10.5772/intechopen.74070

[18] Nersesian E, Spryszynski A, Lee MJ. Integration of Virtual Reality in Secondary STEM Education. In 2019 IEEE Integrated STEM Education Conference (ISEC) 2019 Mar 16 (pp. 83-90). https://doi.org/10.1109/isecon.2019.8882070

[19] Bennett JA, Saunders CP. (2019). A virtual tour of the cell: impact of virtual reality on student learning and engagement in the STEM classroom. Journal of Microbiology \& Biology Education, 20. https://doi.org/10.1128/jmbe.v20i2.1658

[20] Huang KT, Ball C, Francis J, Ratan R, Boumis J, Fordham J. (2019). Augmented versus virtual reality in education: An exploratory study examining science knowledge retention when using augmented reality/virtual reality mobile applications. Cyberpsychology, Behavior, and Social Networking, 22: 105-110. https://doi.org/10.1089/cyber.2018.0150

[21] Tsichouridis C, Batsila M, Vavougios D, Ioannidis G. Virtual and Augmented Reality in Science Teaching and Learning. In International Conference on Interactive Collaborative Learning 2019 Sep 25 (pp. 193-205). https://doi.org/10.1007/978-3-030-40274-7 20

[22] Chalhoub J, Ayer SK. (2018). Using mixed reality for electrical construction design communication. Automation in Construction, 86: 1-10. https://doi.org/10.1016/j.autcon.2017.10.028

[23] Nandavar A, Petzold F, Nassif D, Schubert G, Ag B. (2018). Interactive Virtual Reality Tool for BIM Based on IFC. In Learning, Adapting and Prototyping, Proceedings of the 23rd International Conference of the Association for Computer-Aided Architectural Design Research in Asia (CAADRIA) 2018 (pp. 453-462).

[24] Sampaio AZ, Santos JP, Gomes AR, Rosário DP. (2012). Construction and maintenance planning supported on virtual environments. Virtual Reality-Human Computer Interaction, Rijeka, 125-152. https://doi.org/10.5772/46409

[25] Onime CE, Uhomoibhi J, Pietrosemoli E. (2015). An augmented virtuality based solar energy power calculator in electrical engineering. International Journal of Engineering Pedagogy (iJEP), 5: 4-7. https://doi.org/10.3991/ijep.v5i1.3841 


\section{Authors}

Verónica Paola Rossado Espinoza is an Architect from Ricardo Palma University, Peru, with a master's degree in Higher Teaching and $\mathrm{PhD}$ in Education. She has more than 30 years of experience in architecture design and teaching with digital systems. She currently is a professor at University of Lima in the Faculty of Engineering and Architecture. She often works as reviewer and writer for international conferences and scientist articles.

Daniel Cárdenas-Salas has more than 18 years of experience in process analysis, application development, project management, IT operations and software security. $\mathrm{He}$ is a Systems Engineer (summa cum laude) from University of Lima in Peru and holds a master's degree in Technology Innovation Management from Carleton University (Canada). He is currently in charge of an innovation laboratory at University of Lima.

Angela del Pilar Cabrera Lau is an architect, has more than 33 years of experience in building construction, 20 years of experience teaching in several universities, a master's degree in modern construction management and is currently a professor at University of Lima in courses related to water networks, drainage, and electrical systems in buildings.

Lucia Cristina Coronel Castromonte is a currently a student of the master's in science at Politecnico di Milano in the fields of Urban Planning and Policy Design. She holds a bachelor's degree in architecture and a diploma of specialty in History and Conservation of Architectural Heritage at University of Lima. She is certified by Autodesk in Revit Architecture and Revit MEP tools. She was a researcher collaborator at the Scientific Research Institute (IDIC) at University of Lima in 2016 and 2018.

Article submitted 2020-02-17. Resubmitted 2020-11-14. Final acceptance 2020-11-17. Final version published as submitted by the authors. 